University of Nebraska - Lincoln

DigitalCommons@University of Nebraska - Lincoln

Mechanical \& Materials Engineering Faculty

Publications

Mechanical \& Materials Engineering,

Department of

$6-28-2018$

\title{
Migration resistance of esophageal stents: The role of stent design
}

Hozhabr Mozafari

University of Nebraska-Lincoln, hmozafari2@unl.edu

Pengfei Dong

University of Nebraska-Lincoln, pdong3@unl.edu

Shijia Zhao

University of Nebraska-Lincoln, s-szhao3@unl.edu

Yonghua $\mathrm{Bi}$

First Affiliated Hospital of Zhengzhou University

Xinwei Han

First Affiliated Hospital of Zhengzhou University, dreamweaver08@126.com

See next page for additional authors

Follow this and additional works at: https://digitalcommons.unl.edu/mechengfacpub

Part of the Mechanics of Materials Commons, Nanoscience and Nanotechnology Commons, Other Engineering Science and Materials Commons, Other Mechanical Engineering Commons, and the Surgical Procedures, Operative Commons

Mozafari, Hozhabr; Dong, Pengfei; Zhao, Shijia; Bi, Yonghua; Han, Xinwei; and Gu, Linxia, "Migration resistance of esophageal stents: The role of stent design" (2018). Mechanical \& Materials Engineering Faculty Publications. 387.

https://digitalcommons.unl.edu/mechengfacpub/387

This Article is brought to you for free and open access by the Mechanical \& Materials Engineering, Department of at DigitalCommons@University of Nebraska - Lincoln. It has been accepted for inclusion in Mechanical \& Materials Engineering Faculty Publications by an authorized administrator of DigitalCommons@University of Nebraska Lincoln. 
Authors

Hozhabr Mozafari, Pengfei Dong, Shijia Zhao, Yonghua Bi, Xinwei Han, and Linxia Gu 


\title{
Migration resistance of esophageal stents: The role of stent design
}

\author{
Hozhabr Mozafari,, ${ }^{1}$ Pengfei Dong, ${ }^{1}$ Shijia Zhao, ${ }^{1}$ \\ Yonghua $\mathrm{Bi}^{2}$ Xinwei Han, ${ }^{2}$ Linxia $\mathrm{Gu}^{1,2,3}$
}
1 Department of Mechanical and Materials Engineering, University of Nebraska-Lincoln, Lincoln, NE, 68588-0656, USA
2 Department of Interventional Radiology, The First Affiliated Hospital of Zhengzhou University, Henan Province, China
3 Nebraska Center for Materials and Nanoscience, Lincoln, NE, 68588-0656, USA

Corresponding authors - Department of Mechanical and Materials Engineering, University of NebraskaLincoln, Lincoln, NE, 68588, USA; email hanxinwei2006@163.com (X. Han), Igu2@unl.edu (L. Gu)

\begin{abstract}
Objective: Stenting is one of the major treatments for malignant esophageal cancer. However, stent migration compromises clinical outcomes. A flared end design of the stent diminishes its migration. The goal of this work is to quantitatively characterize stent migration to develop new strategies for better clinical outcomes.

Methods: An esophageal stent with flared ends and a straight counterpart were virtually deployed in an esophagus with asymmetric stricture using the finite element method. The resulted esophagus shape, wall stress, and migration resistance force of the stent were quantified and compared.

Results: The lumen gain for both the flared stent and the straight one exhibited no significant difference. The flared stent induced a significantly larger contact force and thus a larger stress onto the esophagus wall. In addition, more migration resistance force was required to pull the flared stent through the esophagus. This
\end{abstract}

Published in Computers in Biology and Medicine 100 (2018) 43-49

doi 10.1016/j.compbiomed.2018.06.031

PMID: 29975854

Copyright (C) 2018 Elsevier Ltd. Used by permission.

Submitted 3 May 2018; revised 26 June 2018; accepted 26 June 2018; published 28 June 2018. 
force was inversely related to the occurrence rate of stent migration. A doubled strut diameter also increased the migration resistance force by approximately $56 \%$. An increased friction coefficient from 0.1 to 0.3 also boosted the migration resistance force by approximately $39 \%$.

Summary: The mechanical advantage of the flared stent was unveiled by the significantly increased contact force, which provided the anchoring effect to resist stent migration. Both the strut diameter and friction coefficient positively correlated with the migration resistance force, and thus the occurrence of stent migration.

Keywords: Migration, Esophageal stent, Flared, Finite element method, Stent design

\section{Introduction}

Esophageal cancer (EC) is the sixth most common cancer and rarely curable with high morbidity and mortality all over the world [1]. Mostly, the patients suffering from EC are diagnosed at later or advanced stage, which are unfavorable for surgical resection. The survival rate of patients accepting surgical resection is poor with a 5-year survival of 15-34\% [2]. Moreover, palliative care of serious illness like malignant stricture is to relieve the symptoms but unable to inhibit the tumor cells, which is the prime concern in curing EC [3]. Stent, a mesh structure serving as a scaffold to open the palliate esophageal stricture and relieve dysphagia, is becoming a common EC treatment option for improving the quality of life of patients [4]. Various self-expanding metal stents have been developed for this purpose. Major complications include stent migration, tumor ingrowth, and tissue perforation [5,6]. Homann et al. [7] investigated 164 self-expanding stents implanted in malignant strictures of the esophagus or the esophagogastric junction, and observed more stent migration and fewer food impactions in patients implanted with covered stents than with uncovered ones. Most existing efforts focus on the covered materials [8] and their anchoring technique [9]. For example, the endoscopic clip at the upper flare of the covered esophageal stent was considered as one promising means to reduce stent migration [9].

The stent shape was also considered as an important factor influencing stent migration. The most common implementation in the design of esophageal stents was the relatively wider proximal and distal ends, which were used to increase the radial force and reduce the risk of stent migration [10]. Sharma et al. [11] have conducted a critical review of the efficacy of esophageal stents and implied that the underlying mechanism of stent migration and tumor in-growth could be clarified quantitatively. Garbey et al. [12] developed a simplified mathematical model to study the influence of flares design, stent length as well as the radial 
and longitudinal stiffness on the esophageal stent migration. Kajzar et al. [13] illustrated the mechanics of the stent-esophagus system with focus on the crimping and expansion of esophageal stent. Even though Park et al. [5] classified four levels of stent migration in patients with malignant esophageal stricture, the underlying mechanisms of stent migration away from the esophageal stricture, especially the initiation process, remained to be elucidated. Moreover, the quantitative study of stent-esophagus interaction for evaluating stent migration was lacking [14], nonetheless computational modeling of stents has been extensively used for design and analysis [15-18]. Specifically, layered esophageal wall were modeled to illustrate the mechanics of the gastroesophageal junction [19] and the interface mechanics between the muscle layer and the mucosa-submucosa layer [20].

The goal of this work is to characterize the interactions between the stent and esophagus, to shed light on the mechanism of stent migration as well as to design better esophageal stents. We utilized the finite element approach to depict and compare the mechanics of the esophagus with a malignant stricture, after implantation of self-expanding nitinol stents, with and without flared ends. Following the stent deployment in the esophagus, the lumen gain, strut malapposition, Von Mises stress distributions on the wall of the esophagus, and radial contact force between the stent and esophagus were evaluated for both stents. Moreover, both stents were pulled longitudinally at one end to mimic the worst-case scenario for stent migration. The dynamic sliding forces versus the stent displacements were monitored. The obtained results might lead to better design of the next-generation esophageal stents with reduced migration rate.

\section{Materials and methods}

A three-dimensional geometry of the WallFlex stent (Boston Scientific, Massachusetts, USA) with and without flared ends was constructed as shown in Fig. 1. For the stent without flared ends, the total length was 100 $\mathrm{mm}$ and the outer diameter was $18.22 \mathrm{~mm}$. For the flared stent, the middle section had the same diameter as the straight stent with a length of 64 $\mathrm{mm}$, while the flared ends had a diameter of $24.22 \mathrm{~mm}$ with a length of 9 $\mathrm{mm}$ at each end. Both esophageal stents were braided using 28-strand of wires with the diameter of $0.4 \mathrm{~mm}$ and pitch angle of $45^{\circ}$ [11].

The esophagus was assumed to be a uniform cylinder with a length of $150 \mathrm{~mm}$, an inner diameter of $16 \mathrm{~mm}$, and a wall thickness of $3 \mathrm{~mm}$ 

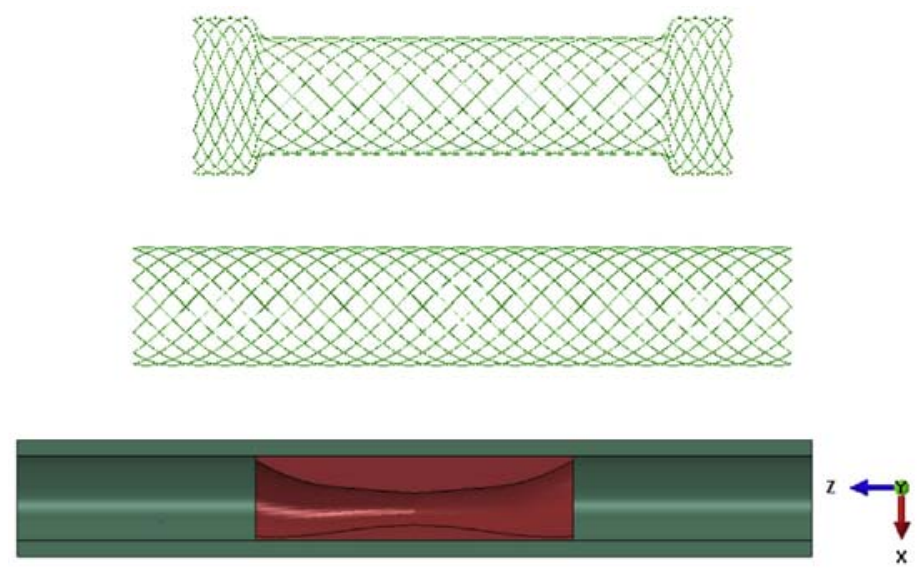

b

Fig. 1. (A) Configurations of the flared stent and straight one; (b) Tumor restricted Esophagus.

[14]. The simplified esophagus tube has been used for understanding the food transport [21], and stent-esophagus system [13]. The eccentricshaped tumor with a maximum thickness ratio of 2:1 spanned across the $60 \mathrm{~mm}$ of esophagus and resulted in a minimum lumen diameter of 6 $\mathrm{mm}$, i.e., a diametrical stenosis ratio of $62.5 \%$ (Fig. 1b). The tumor length was shorter than the middle section of the flared stent, and this warranted the same stent-tumor interaction for both stent deployments. After preliminary simulations, we constructed half of the model by applying symmetry boundary conditions along the $z$ plane $\left(U_{z}=U R_{x}=U R_{y}=0\right)$ in order to reduce the computational time.

The stent was made of nitinol which underwent phase transformation between austenite and martensite during one loading cycle [22]. The superelastic behavior of shape memory alloys can be simply understood as the phase transformation of austenite and martensite under stress. Based on free energy function and dissipation potential, the model is assumed that there is a relationship between the martensitic constant $\varphi_{M}$ and the austenite constant $\varphi_{A}$ :

$$
\varphi_{M}+\varphi_{A}=1
$$

The elastic modulus of Nitinol can be represented as a linear function of martensite volume fraction

$$
E_{f}=\varphi_{M} E_{M}+\left(1-\varphi_{M}\right) E_{A}
$$

where $E_{f}, E_{M}$ and $E_{A}$ are the elastic modulus of alloy, martensite and austenite, respectively. 
Table 1. Material constants of Nitinol.

\begin{tabular}{lll} 
Property & Value & Definition \\
\hline$E_{A}$ & $50 \mathrm{GPa}$ & Austenite elasticity \\
$E_{M}$ & $37 \mathrm{GPa}$ & Martensite elasticity \\
$\sigma_{M}^{s}$ & $400 \mathrm{MPa}$ & Starting transformation stress of loading \\
$\sigma_{M}^{f}$ & $650 \mathrm{MPa}$ & End transformation stress of loading \\
$\sigma_{A}^{s}$ & $350 \mathrm{MPa}$ & Starting transformation stress of unloading \\
$\sigma_{A}^{f}$ & $80 \mathrm{MPa}$ & End transformation stress of unloading \\
$\varepsilon_{L}$ & 0.055 & Maximum residual strain \\
\hline
\end{tabular}

The stress-strain relation is given according to the generalized Hooke's law as follows:

$$
\sigma_{f}=C_{f}\left(\varepsilon-\alpha\left(T-T_{0}\right)-\varepsilon_{t r}\right)
$$

where $\varepsilon$ is the total strain the SMA, $\mathrm{T}_{0}$ is the reference temperature, $\varepsilon_{t r}$ is the phase transformation strain, $\alpha$ is the thermal coefficient, $\sigma_{f}$ and $C_{f}$ are the stress and elastic tensor, respectively. Therefore, an incremental constitutive law can be expressed as:

$$
\Delta \sigma_{f}=C_{f}\left(\varphi_{M}\right)\left(\Delta \varepsilon-\alpha\left(\varphi_{M}\right) \Delta T-\omega \Delta \varphi_{M}\right)
$$

The main parameters of the constitutive model of nitinol alloy under isothermal conditions were listed in Table 1 [23]. The constitutive model was implemented through a built-in ABAQUS user material subroutine (UMAT) [24].

The hyperelastic behavior of the tissue, including both esophagus and tumor, were adopted from the published experimental datasets [23,25], which were fitted using the reduced polynomial constitutive equation below:

$$
U=\sum_{i, j=1}^{3} C_{i j}\left(I_{1}-3\right)^{i}\left(I_{2}-3\right)^{j}
$$

where, $I_{7}$ and $I_{2}$ are the first and second invariants of the Cauchy-Green tensor and

$$
\begin{aligned}
& I_{1}=\lambda_{1}{ }^{2}+\lambda_{2}{ }^{2}+\lambda_{3}{ }^{2} \\
& I_{2}=1 / \lambda_{1}{ }^{2}+1 / \lambda_{2}{ }^{2}+1 / \lambda_{3}{ }^{2}
\end{aligned}
$$

The obtained material coefficients $C_{\mathrm{ij}}$ are listed in Table 2. 
Table 2. Material coefficients of both esophagus and tumor (units: MPa).

\begin{tabular}{ll}
\hline Esophagus (Based on the axil testing of mucosa) & $C_{10}=-0.0268$ \\
& $C_{01}=0.0479$ \\
& $C_{20}=0.81218$ \\
& $C_{11}=-1.7233$ \\
& $C_{02}=0.98173$ \\
& $C_{10}=0.039$ \\
Tumor & $C_{20}=0.0031$ \\
& $C_{30}=0.02976$ \\
\hline
\end{tabular}

The stent crimping process was simulated by applying radial inward displacement on the outer surface of the stent. The self-expanding process was captured by removing the displacement constrains. No relative movement between braided wires was allowed to mimic the role of the cover on the stent. The residual stresses of the esophagus tissue under physiological loading conditions were not considered for this comparative study [26]. The friction coefficient of 0.1 was adopted for the contact between the stent wires and tissue [27]. The mesh convergence study was conducted, and the esophagus and tumor was meshed with 125,000 and 21,456 elements (C3D8R), respectively. The stent was constructed by 11,200 B31 elements which are two-node elements with one integration point in the middle and have been used for modeling of stents [28,29].

Following the stent deployment in the esophagus, a longitudinal displacement of $60 \mathrm{~mm}$ was prescribed on the left end of the stent till it slid through the esophagus. The required sliding force during the sliding process was monitored.

\section{Results}

\subsection{Interactions among stent, tumor and esophagus}

Stent lumen enlargement and stress distribution are shown in Fig. 2. The minimal lumen diameter increased from $6 \mathrm{~mm}$ to $17.15 \mathrm{~mm}$ and $16.91 \mathrm{~mm}$ for the flared stent and straight one, respectively. The stent ends resulted in an increased lumen diameter from $16 \mathrm{~mm}$ to $24.09 \mathrm{~mm}$ and $18.06 \mathrm{~mm}$ for the flared stent and straight one, respectively. The incomplete stent strut apposition, also referred to as malapposition, was characterized by the area of the non-contact region between the stent and tissue. The malapposition area was $532.80 \mathrm{~mm}^{2}$ and $171.04 \mathrm{~mm}^{2}$ for the flared stent 

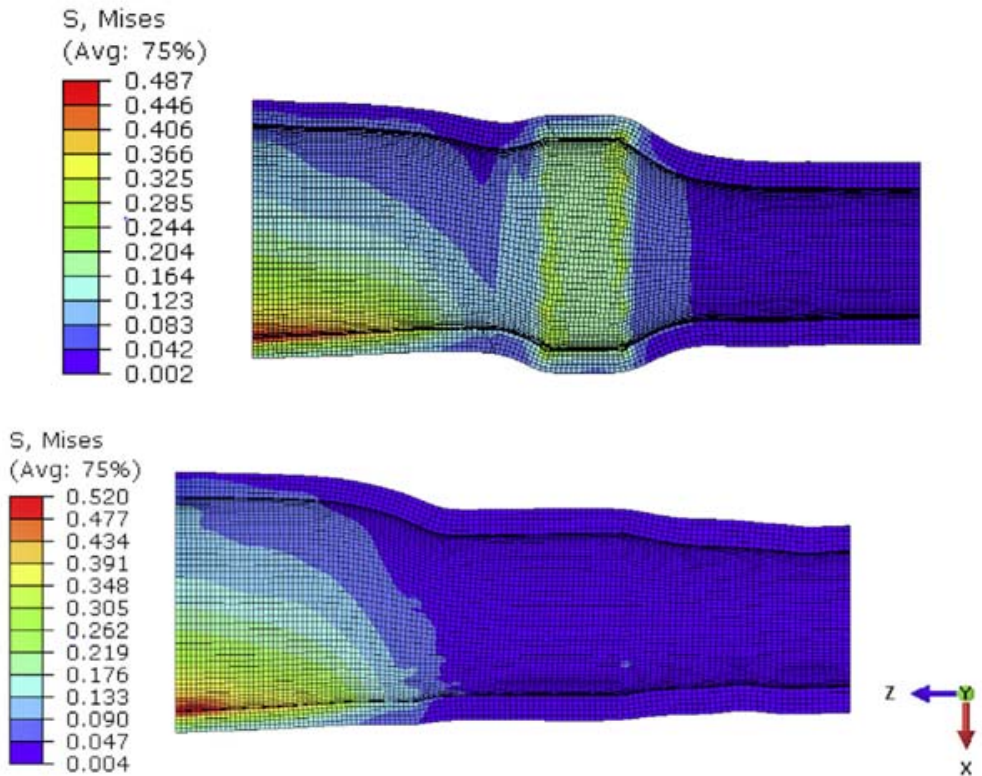

Fig. 2. Stress distribution on the esophageal wall induced by flared stent or (top) or straight one (bottom).

and the straight one, respectively. The corresponding maximum gap between the stent and the tissue was $2.29 \mathrm{~mm}$ and $0.746 \mathrm{~mm}$ for the flared and straight stents, respectively. It is clear that the flared stent induced more malapposition compared to the straight one.

The Von Mises stress concentration in the esophagus was located in the middle of the tissue, specifically at the narrowest lumen region, regardless of stent design. The peak stress on the esophageal wall was approximately $520 \mathrm{kPa}$ induced by the straight stent and $530 \mathrm{kPa}$ by the flared stent. The stress distributions on the middle region of the stented esophagus were similar for both stents. However, the Von Mises stress at the flared-end region was up to $410 \mathrm{kPa}$, which was much higher than that induced by the straight stent. The peak stress of esophagus was within the reported ultimate tensile strength of muscle layer, i.e., 425$530 \mathrm{kPa}[30]$.

\subsection{Migration dynamics}

The dynamics of stent migration were studied by pulling both expanded stents out of the esophagus as illustrated in Fig. 3. The anchoring effect of the flared end and straight one is demonstrated using snapshots. As the right end of the stent was about to pass the narrowest tumor 


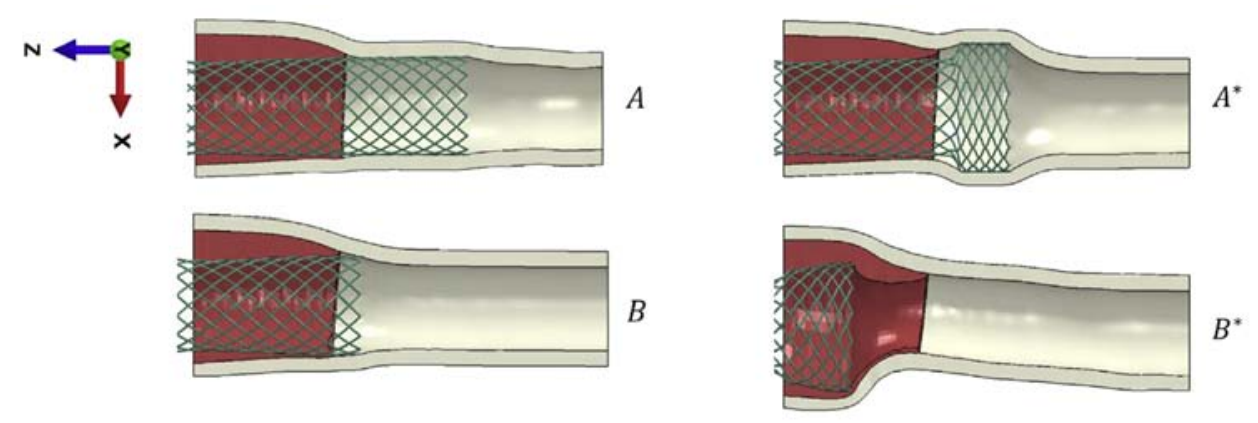

Fig. 3. Snapshots of pulling both (a) flared stent and (b) straight stent, representing the initial configuration ( $A$ and $\left.A^{*}\right)$ and peak resistance force $\left(B\right.$ and $\left.B^{\star}\right)$.

location, the maximum pulling force, also referred to as the migration resistance force, occurred for both stents. Afterward, a decline in the magnitude of force was observable when the stent was leaving the tumor region.

During the pulling, the contact forces at the stent-tissue interface were monitored as shown in Fig. 4. The contact force here excluded the middle section of both stents with a length of $64 \mathrm{~mm}$ due to the minimal variations between stents. Clearly, the flared ends induced a higher contact force than the straight one. Before the stent migration initiated at $0.04 \mathrm{~s}$, the contact forces were $31.5 \mathrm{~N}$ for the flared stent and 6.6 $\mathrm{N}$ for the straight one. The pulling motion dramatically increased the

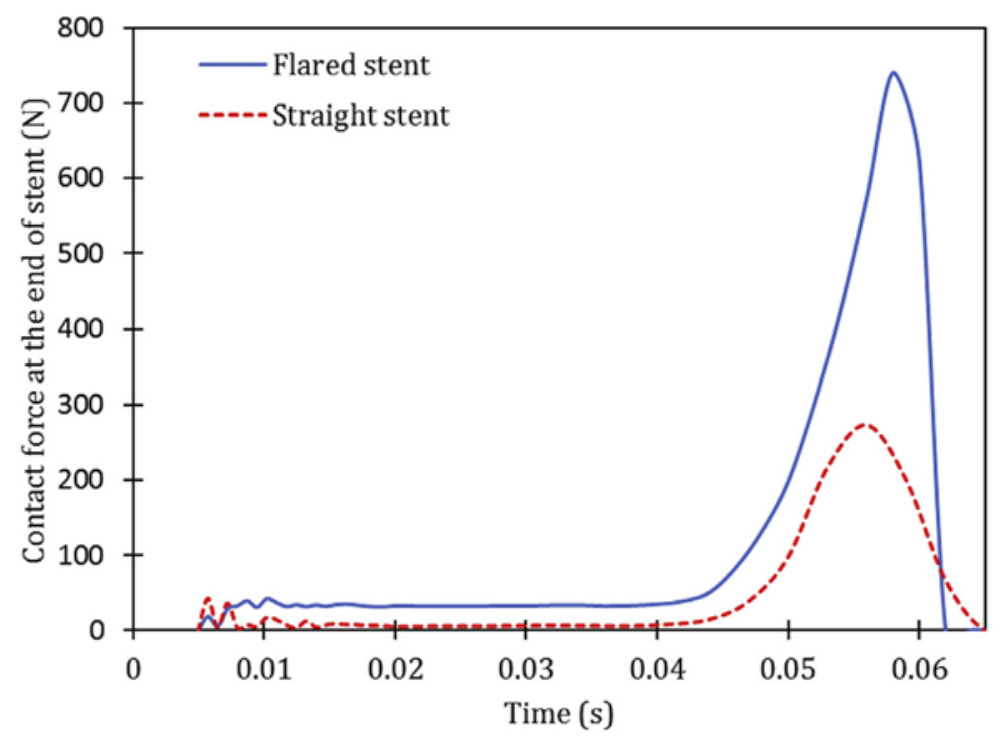

Fig. 4. Contact force time history for both flared and straight stents. 


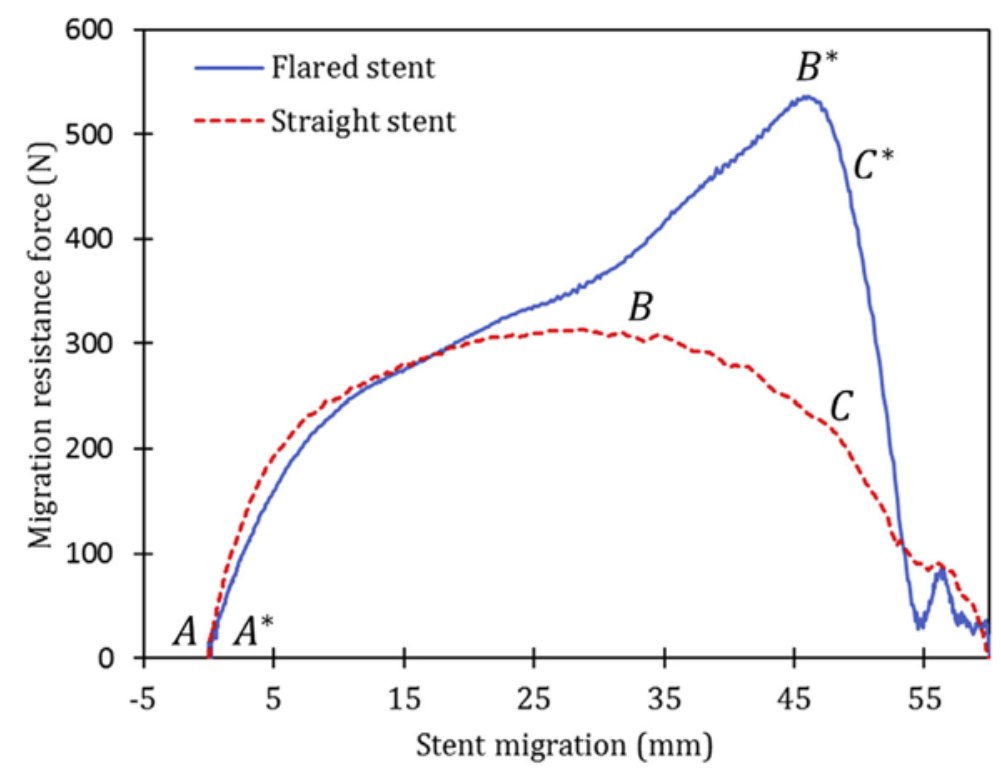

Fig. 5. The migration resistance force in relation to the migration distance of stents.

corresponding contact force up to $741 \mathrm{~N}$ and $273 \mathrm{~N}$, respectively. Considering the flared end was only half the length of the straight one, the flared end design boosted the contact even more. The higher contact force implied a larger migration resistance potential.

Fig. 5 depicts the migration resistance force during the pulling process. The flared stent exhibited a sharp increase in the migration resistance force. After reaching the peak magnitude, i.e., overcoming the tumor edges (Fig. 3), an abrupt decline in resistance force was observed. The uniformity of the straight stent resulted in the gradual change in the migration resistance force. In addition, the peak migration resistance force for the flared and straight stents were $535 \mathrm{~N}$ and $310 \mathrm{~N}$, respectively. This indicated that the required axial load to move the flared stent through the esophagus is $72.5 \%$ higher than that for the straight stent. In addition, the anchoring effect could be calculated as the elastic strain energy, which was $9 \mathrm{~J}$ and $4.8 \mathrm{~J}$ for the flared and straight stents, respectively.

The role of the nitinol wire diameter and the friction coefficient between stent wires and tissue on the migration resistance force were depicted to facilitate a better design of the stents (Fig. 6). The wire diameter impacted the migration force dramatically. Specifically, the migration resistance force of the stent with a wire diameter of $0.6 \mathrm{~mm}$ was $834 \mathrm{~N}$ which is $56.5 \%$ and $164 \%$ greater than that for the stents with wire diameters of $0.4 \mathrm{~mm}$ and $0.3 \mathrm{~mm}$, respectively. Moreover, the peak migration 

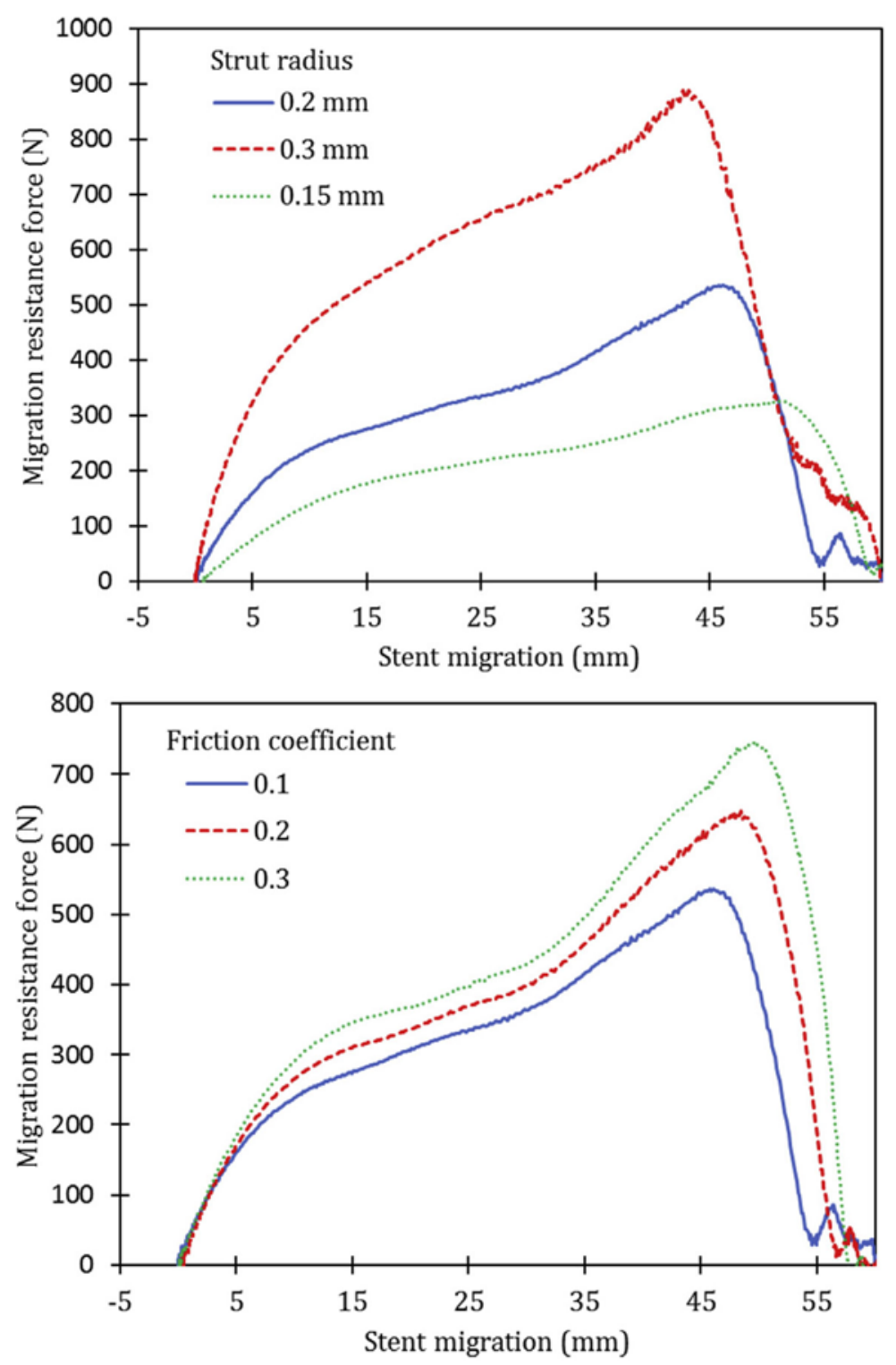

Fig. 6. The migration resistance force of the flared stent in response to the wire diameter (Top) and the friction coefficient between stent wires and tissue (bottom).

force was delayed with a thinner wire. This could be explained by the rigidity of the stent, which was reduced with a thinner wire.

The friction coefficient between the wires and tissue also influenced the migration risk of the stents. The migration resistance responses demonstrated the same trend. The maximum migration resistance forces for the friction coefficients of $0.1,0.2$ and 0.3 were $535 \mathrm{~N}, 639.42 \mathrm{~N}$ and $741.91 \mathrm{~N}$, respectively. A larger friction coefficient of 0.3 caused $38.67 \%$ enhancement of the migration resistance force, compared to the coefficient of 0.1 . 


\section{Discussion}

Esophageal stent insertion provides a substantial advantage in the management of dysphagia in patients with malignant esophageal obstruction. However, stenting complications compromise the quality of the patient's life. Stent migration is one of the major complications associated with esophageal stent implantations [31-33]. Fig. 7 illustrates that the esophageal covered stent migrated downward $1 \mathrm{~cm}$ after 20 days of placement for treating the gastroesophageal anastomotic fistula of a 65-year old male patient. The informed consent was obtained from the patient to showing the image, which was achieved from digital subtraction angiography (DSA) during stenting procedure. Despite the extensive clinical observations regarding esophageal stent complications, there are limited studies on the mechanistic understanding of stent migration.

This motivated us to test the role of flared ends, braided wire diameter, and the friction coefficient between wires and tissue on stent migration. We utilized the finite element method, which has the advantage of replicating the physical problems with low-cost complex geometry, compared to both experimental tests and analytical methods. Experimental tests are usually expensive to conduct and difficult to isolate specific parameters. Analytical methods are limited to idealized geometries and boundary conditions. In this work, we have constructed finite

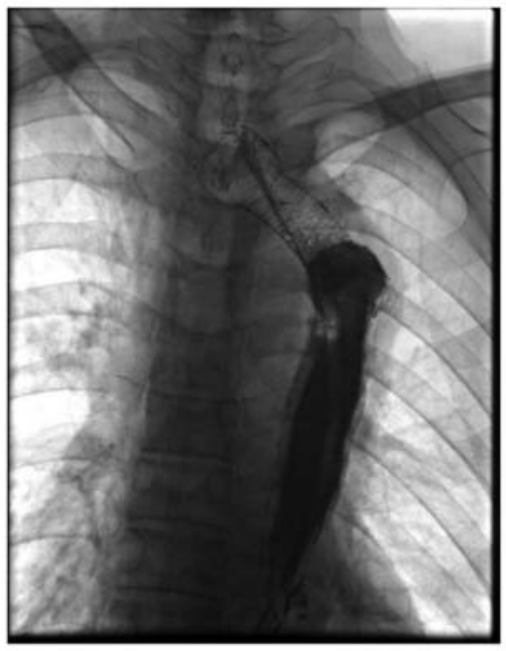

(a)

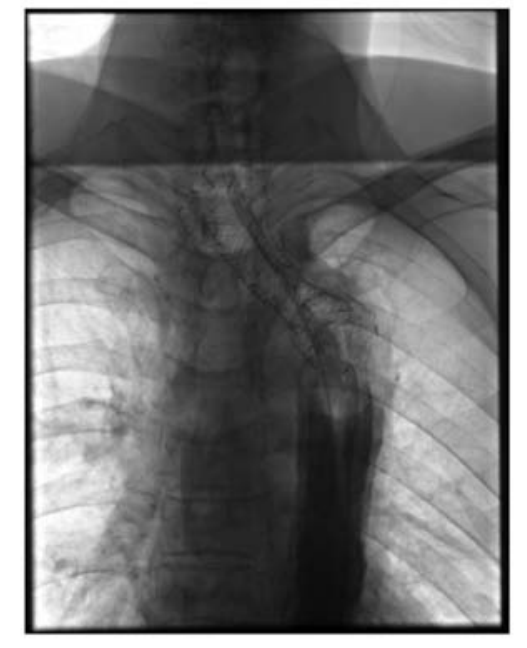

(b)

Fig. 7. Digital subtraction angiography of the esophageal stent placement (a) and migration down $1 \mathrm{~cm}$ after 20 days (b). 
element models to simulate the deployment of stents in the esophagus and then applied axial loading to characterize the migration risk of the stents.

Our modeling framework was validated against the published experimental data of a braided self-expandable Wallstent (Boston Scientific, Natick, MA) by Jedwab and Clerc [34]. The aforementioned modeling techniques were used to construct a braided Wallstent with a nominal length of $87.5 \mathrm{~mm}$, braiding strand number of 24 , braiding angle of $30.85^{\circ}$, strand diameter of $0.22 \mathrm{~mm}$, and outer diameter of $17.15 \mathrm{~mm}$. The stent was made of Cobalt-Chromium-Nickel (Co-Cr-Ni) alloy with a Young's modulus of $206 \mathrm{GPa}$, shear modulus of $81.5 \mathrm{GPa}$, and yield strength of $2.5 \mathrm{GPa}$. Our simulation of the axial tension of the stent agreed very well with the experimental and theoretical data (Fig. 8). Following the validation, our model could be used to delineate the interaction between the stents and tissue and to predict the tendency of stent migration.

Our results have demonstrated that the flared ends induced a much larger radial contact force (Fig. 4). Following stent deployment, the contact force of the flared ends was 4.77 times more than that of the straight ones. The contact force of the flared ends per unit length was 9.54 times larger than that of the straight ones. This could be explained by overstretch of the esophageal wall at the flared ends. This implied that the flared ends serve as anchors to maintain the deployment location and mitigate stent migration. However, larger contact force led to higher

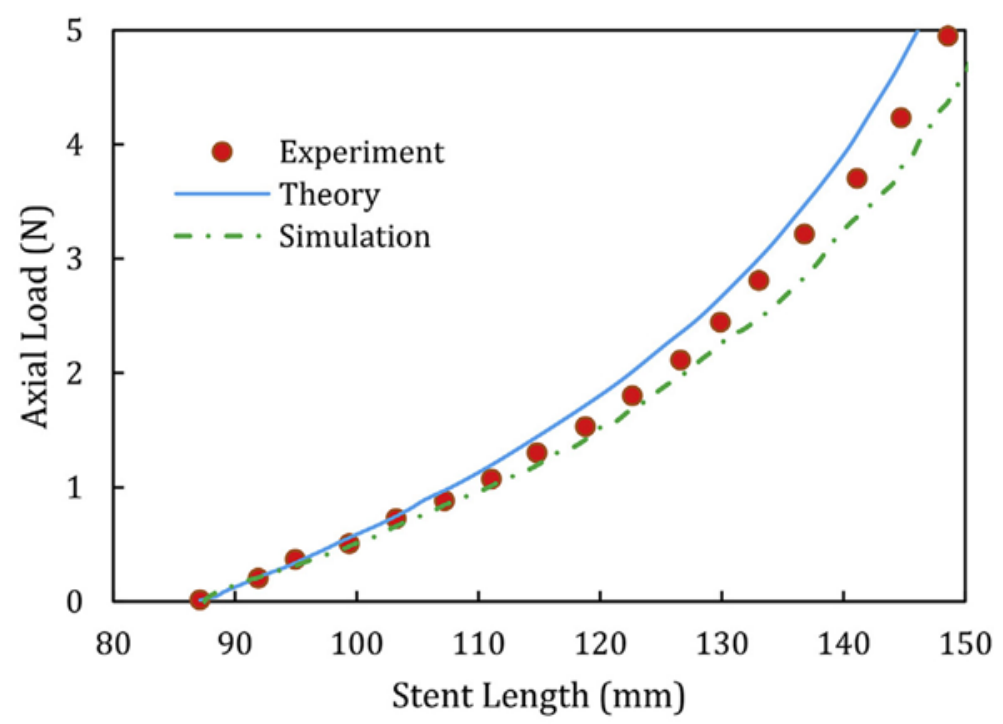

Fig. 8. Axial tension load of a braided stent in relation to the stent length. 
stresses on the esophageal wall for both stents. This might cause the esophagus damage and failure. Stavropoulou et al. [35] studied the failure criteria for mucosa-submucosa and muscle layers of esophagus. The ultimate tensile strength of mucosa-submucosa and muscle layers were reported as $1149 \mathrm{kPa}$ and $425-530 \mathrm{kPa}$, respectively. The stronger mucosa-submucosa layer was associated with its higher collagen content. The higher peak stress of esophagus induced by flared stent could lead to a higher probability of tissue damage.

During the axial pulling of the stent through the esophagus, the radial contact force increased dramatically for both stents. However, the relative difference between the flared stent and the straight one was reduced to a ratio of 2.71 . This could indicate that the peristaltic contraction that pushes the food through the esophagus might appreciate the flared stent less. The esophageal contraction is usually preceded by a transient variations of pressure in radial and longitudinal directions. This may represent tongue or laryngeal movement or changes in respiration coincident with the initiation of the swallow [36]. Even though the peristaltic contraction was essential for bolus transport through esophagus tube [37,38], it could be simplified as the axial pulling of the stent through the esophagus for the comparative study of the migration risk.

During the pulling of the stents, much more work was required to initiate sliding of the flared stent than the straight one (Fig. 5). In addition, the straight stent sliding initiated gradually, and the flared stent exhibited a sharp resistance force with a larger magnitude. Again, this was due to the anchoring effect of the flared ends.

Our results provided the quantitative datasets for better understanding the observations in both clinical trials and animal studies. Els et al. [33] examined 46 patients and found that flared stents mitigated stent migration. The rabbit study also demonstrated that a flared prostatic stent helped to reduce migration compared to its straight counterpart [39].

Various sizes of wires have been used to braid the stent. Our results have shown that a doubled wire diameter increased the migration resistance force by 1.64 times. This indicates that a thicker wire for the stent could be adopted for reduced probability of migration. This could be explained by increased rigidity of the stent when fabricated using thicker wires. More stretch along the esophagus length would be expected at the same pulling load.

We also tested how the friction coefficient between stent wires and tissue affects the migration resistance since this coefficient was rarely 
reported. Usually an assumed value was adopted [14]. It was found that the friction coefficient has a considerable impact on the risk of stent migration. If we tripled the friction coefficient, the peak migration resistance force was $38.67 \%$ larger. This indicated that the surface treatment of the stent wires, or struts, for increasing the friction coefficient, could also prevent the risk of stent migration.

In the present model, the relative movement of the braided wires was constrained using tie command at contact surfaces to mimic the covering effect commonly used in commercial esophageal stents. The anatomical details of the esophagus including the stellate appearance of the inner esophageal layer [14] was simplified as an esophagus tube with a friction coefficient. A range of friction coefficients were used depending on relative movement between the stent and the esophageal wall [22]. A larger friction coefficient was commonly associated with the less migration risk. The feasibility of the model was validated in our previous work $[40,41]$. The esophagus was modeled as a one-layer tube [13,42], although it is assumed as two layer [43,44] or three layer wall [45] depending on the aim of the study. The detailed configurations of esophageal wall could alter our results in terms of magnitudes, but the comparative results between two stent designs was expected to be the same. The material properties of the esophagus and cancerous tissue were assumed to be homogeneous isotropic materials, although they are anisotropic [46]. The perfect plasticity for cancerous tissue was assumed due to lack of experimental data. More realistic models considering patientspecific geometry and anisotropic three-layered esophageal wall properties would change the contact force and the migration resistance force. The existence of pre-stretch along axial and circumferential directions at physiological conditions [26] as well as the esophageal muscle contraction were not explicitly incorporated in our model, we speculate that the both pre-stretch and wall contraction were associated with the reduced friction between stent and esophagus, and thus a higher migration rate. Despite these simplifications, this work demonstrated the importance of the stent design on the risk of migration, which might have significant clinical implications. This work could be used to provide a fundamental understanding of the behavior and impact of stent design on the esophageal wall, provide guidance for optimizing stent shape and surface profiles, and illuminate the possibilities for exploiting their potential to prevent migration.

Acknowledgments - Financial support from the National Science Foundation CAREER award (CBET-1254095) is acknowledged. 


\section{References}

[1] M. Shaikh, N.R. Choudhury, R. Knott, S. Garg, Engineering stent based delivery system for esophageal cancer using docetaxel, Mol. Pharm. 12 (7) (2015) 2305-2317.

[2] K.M. Sjoquist, B.H. Burmeister, B.M. Smithers, J.R. Zalcberg, R.J. Simes, A. Barbour, V. Gebski, A.G.-I.T. Group, Survival after neoadjuvant chemotherapy or chemoradiotherapy for resectable oesophageal carcinoma: An updated meta-analysis, Lancet Oncol. 12 (7) (2011) 681-692.

[3] Z. Jin, K. Wu, J. Hou, K. Yu, Y. Shen, S. Guo, A PTX/nitinol stent combination with temperature-responsive phase-change 1-hexadecanol for magnetocaloric drug delivery: Magnetocaloric drug release and esophagus tissue penetration, Biomaterials 153 (2018) 49-58.

[4] G. Lazaraki, I. Pilpilidis, P. Katsinelos, Polyflex stents for malignant esophageal strictures: An overview, Ann. Gastroenterol. 23 (1) (2010) 17-23.

[5] J.-H. Park, H.-Y. Song, J.H. Shin, Y.C. Cho, J.H. Kim, S.H. Kim, J. Park, Migration of retrievable expandable metallic stents inserted for malignant esophageal strictures: Incidence, management, and prognostic factors in 332 patients, Am. J. Roentgenol. 204 (5) (2015) 1109-1114.

[6] P. Hindy, J. Hong, Y. Lam-Tsai, F. Gress, A comprehensive review of esophageal stents, Gastroenterol. Hepatol. 8 (8) (2012) 526-534.

[7] N. Homann, M.R. Noftz, R.D. Klingenberg-Noftz, D. Ludwig, Delayed complications after placement of self-expanding stents in malignant esophageal obstruction: Treatment strategies and survival rate, Dig. Dis. Sci. 53 (2) (2008) 334-340.

[8] W.C. Wu, R.M. Katon, R.R. Saxon, R.E. Barton, B.T. Uchida, F.S. Keller, J. Rösch, Silicone-covered self-expanding metallic stents for the palliation of malignant esophageal obstruction and esophagorespiratory fistulas: Experience in 32 patients and a review of the literature, Gastrointest. Endosc. 40(1) 22-33.

[9] G. Vanbiervliet, J. Filippi, B.S. Karimdjee, N. Venissac, A. Iannelli, A. Rahili, E. Benizri, D. Pop, P. Staccini, A. Tran, S. Schneider, J. Mouroux, J. Gugenheim, D. Benchimol, X. Hébuterne, The role of clips in preventing migration of fully covered metallic esophageal stents: A pilot comparative study, Surg. Endosc. 26 (1) (2012) 53-59.

[10] K.L. Franco, J.B. Putnam, Advanced Therapy in Thoracic Surgery, second ed., B.C. Decker Inc, Hamilton, 2005.

[11] P. Sharma, R. Kozarek, Role of esophageal stents in benign and malignant diseases, Am. J. Gastroenterol. 105 (2) (2010) 258.

[12] M. Garbey, R. Salmon, V. Fikfak, C.O. Clerc, Esophageal stent migration: Testing few hypothesis with a simplified mathematical model, Comput. Biol. Med. 79 (2016) 259-265.

[13] W. Kajzer, M. Kaczmarek, J. Marciniak, Biomechanical analysis of stentoesophagus system, J. Mater. Process. Technol. 162-163 (2005) 196-202. 
[14] M. Peirlinck, N. Debusschere, F. lannaccone, P.D. Siersema, B. Verhegghe, P. Segers, M. De Beule, An in silico biomechanical analysis of the stentesophagus interaction, Biomechanics Model. Mechanobiol. 17 (1) (2018) 111-131.

[15] S. Zhao, X. Liu, L. Gu, The impact of wire stent fabrication technique on the performance of stent placement, Journal of Medical Devices-Transactions of the ASME 6 (1) (2012).

[16] A. García, E. Peña, M.A. Martínez, Influence of geometrical parameters on radial force during self-expanding stent deployment. Application for a variable radial stiffness stent, Journal of the Mechanical Behavior of Biomedical Materials 10 (Supplement C) (2012) 166-175.

[17] M. De Beule, P. Mortier, S.G. Carlier, B. Verhegghe, R. Van Impe, P. Verdonck, Realistic finite element-based stent design: the impact of balloon folding, J. Biomech. 41 (2) (2008) 383-389.

[18] C. Lally, F. Dolan, P.J. Prendergast, Cardiovascular stent design and vessel stresses: a finite element analysis, J. Biomech. 38 (8) (2005) 1574-1581.

[19] R. Yassi, L.K. Cheng, V. Rajagopal, M.P. Nash, J.A. Windsor, A.J. Pullan, Modeling of the mechanical function of the human gastroesophageal junction using an anatomically-realistic three-dimensional model, J. Biomech. 42 (11) (2009) 1604-1609.

[20] D. Liao, J. Zhao, Y. Fan, H. Gregersen, Two-layered quasi-3D finite element model of the oesophagus, Med. Eng. Phys. 26 (7) (2004) 535-543.

[21] W. Yang, T.C. Fung, K.S. Chian, C.K. Chong, Finite element simulation of food transport through the esophageal body, World J. Gastroenterol.: WJG 13 (9) (2007) 1352.

[22] S. Zhao, L. Gu, S.R. Froemming, Performance of self-expanding nitinol stent in a curved artery: impact of stent length and deployment orientation, J. Biomech. Eng. 134 (7) (2012) 071007-071007-6.

[23] S. Zhao, L. Gu, S.R. Froemming, Finite element analysis of the implantation of a self-expanding stent: impact of lesion calcification, J. Med. Dev. Trans. ASME 6 (2) (2012) 021001-021001-6.

[24] N. Rebelo, N. Walker, H. Foadian, Simulation of implantable nitinol stents, Abaqus User's Conference, 2001, pp. 1-14.

[25] A.N. Natali, E.L. Carniel, H. Gregersen, Biomechanical behaviour of oesophageal tissues: Material and structural configuration, experimental data and constitutive analysis, Med. Eng. Phys. 31 (9) (2009) 1056-1062.

[26] X. Lu, H. Gregersen, Regional distribution of axial strain and circumferential residual strain in the layered rabbit oesophagus, J. Biomech. 34 (2) (2001) 225-233.

[27] C.X. Lin, Q.Y. Yu, J. Wang, W. Ji, W. Li, Z.R. Zhou, Friction behavior between endoscopy and esophageal internal surface, Wear 376-377 (2017) 272-280.

[28] L. Tan, D. Webb, K. Kormi, S. Al-Hassani, A method for investigating the mechanical properties of intracoronary stents using finite element numerical simulation, Int. J. Cardiol. 78 (1) (2001) 51-67. 
[29] S. Zhao, X. Liu, L. Gu, The impact of wire stent fabrication technique on the performance of stent placement, J. Med. Dev. Trans. ASME 6 (1) (2012) 011007- 011007-4.

[30] K. Van der Heiden, F.J.H. Gijsen, A. Narracott, S. Hsiao, I. Halliday, J. Gunn, J.J. Wentzel, P.C. Evans, The effects of stenting on shear stress: Relevance to endothelial injury and repair, Cardiovasc. Res. 99 (2) (2013) 269-275.

[31] D. Saranovic, A. Djuric-Stefanovic, A. Ivanovic, D. Masulovic, P. Pesko, Fluoroscopically guided insertion of self-expandable metal esophageal stents for palliative treatment of patients with malignant stenosis of esophagus and cardia: Comparison of uncovered and covered stent types, Dis. Esophagus 18 (4) (2005) 230-238.

[32] H.-Y. Song, Y.-S. Do, Y.-M. Han, K.-B. Sung, E.-K. Choi, K.-H. Sohn, H.-R. Kim, S.-H. Kim, Y.-I. Min, Covered, expandable esophageal metallic stent tubes: experiences in 119 patients, Radiology 193 (3) (1994) 689-696.

[33] E.M. Verschuur, M.Y. Homs, E.W. Steyerberg, J. Haringsma, P.J. Wahab, E.J. Kuipers, P.D. Siersema, A new esophageal stent design (Niti-S stent) for the prevention of migration: A prospective study in 42 patients, Gastrointest. Endosc. 63 (1) (2006) 134-140.

[34] J.M. R, C.C. O, A study of the geometrical and mechanical properties of a selfexpanding metallic stent-theory and experiment, J. Appl. Biomater. 4 (1) (1993) 77-85.

[35] E.A. Stavropoulou, Y.F. Dafalias, D.P. Sokolis, Biomechanical behavior and histological organization of the three-layered passive esophagus as a function of topography, Proc. IME H J. Eng. Med. 226 (6) (2012) 477-490.

[36] M.M. Mughal, M. Marples, J. Bancewicz, Scintigraphic assessment of oesophageal motility: What does it show and how reliable is it? Gut 27 (8) (1986) 946-953.

[37] W. Kou, A.P.S. Bhalla, B.E. Griffith, J.E. Pandolfino, P.J. Kahrilas, N.A. Patankar, A fully resolved active musculo-mechanical model for esophageal transport, J. Comput. Phys. 298 (2015) 446-465.

[38] W. Kou, J.E. Pandolfino, P.J. Kahrilas, N.A. Patankar, Simulation studies of circular muscle contraction, longitudinal muscle shortening, and their coordination in esophageal transport, Am. J. Physiol. Gastrointest. Liver Physiol. 309 (4) (2015) G238-G247.

[39] J. Liu, L. Shang, J. Liu, C. Qin, A novel biodegradable esophageal stent: Results from mechanical and animal experiments, Am. J. Tourism Res. 8 (2) (2016) 1108-1114.

[40] L. Gu, S. Zhao, A.K. Muttyam, J.M. Hammel, The relation between the arterial stress and restenosis rate after coronary stenting, J. Med. Dev. Trans. ASME 4 (3) (2010) 031005.

[41] S. Zhao, L. Gu, S.R. Froemming, Experimental investigation of the stent-artery interaction, J. Med. Eng. Technol. 37 (7) (2013) 463-469.

[42] J. Zhao, J. Yang, L. Vinter-Jensen, F. Zhuang, H. Gregersen, Biomechanical properties of esophagus during systemic treatment with epidermal growth factor in rats, Ann. Biomed. Eng. 31 (6) (2003) 700-709. 
[43] Y. Fan, H. Gregersen, G.S. Kassab, A two-layered mechanical model of the rat esophagus. Experiment and theory, Biomed. Eng. Online 3 (1) (2004) 40.

[44] W. Yang, T. Fung, K. Chian, C. Chong, Instability of the two-layered thickwalled esophageal model under the external pressure and circular outer boundary condition, J. Biomech. 40 (3) (2007) 481-490.

[45] D.P. Sokolis, Structurally-motivated characterization of the passive pseudoelastic response of esophagus and its layers, Comput. Biol. Med. 43 (9) (2013) 1273-1285.

[46] W. Yang, T.C. Fung, K.S. Chian, C.K. Chong, 3D Mechanical properties of the layered esophagus: Experiment and constitutive model, J. Biomech. Eng. 128 (6) (2006) 899-908. 